\title{
A emergência do neoliberalismo no Brasil: um estudo sobre a revista Veja no contexto das eleições presidenciais de 1989
}

\author{
Leonardo Brandão \& Michel Honório da Silva \\ Universidade Regional de Blumenau - FURB, Brazil \\ E-mail: brandaoleonardo@uol.com.br/michelcorinthians3594@gmail.com
}

\begin{abstract}
Resumo
Este artigo teve por objetivo analisar a participação da revista Veja no processo de difusão da ideologia neoliberal no Brasil. O recorte temporal proposto enfatizou o último ano da década de 1980, período que compreende a campanha eleitoral que marcou o retorno das eleições diretas para a presidência da República, vencida pelo candidato Fernando Collor de Mello. Partiu-se da hipótese que a revista Veja teve um papel de difusão dessa ideologia, e para

tanto se adotou uma perspectiva de detectar e analisar as representações construídas sobre o neoliberalismo num momento em que esse era muito mais uma promessa do que uma realidade no país. O método de pesquisa ocorreu por meio da análise do discurso, sendo que a ênfase recaiu em editorias, matérias e entrevistas publicadas, e quando se mostrou pertinente, também em reportagens acerca de outros países onde o neoliberalismo vigorava.
\end{abstract}

Palavras-chave: neoliberalismo; revista Veja; história.

\section{The emergence of neoliberalism in Brazil: a study about the magazine Veja in the context of the presidential elections of 1989}

\begin{abstract}
This article aimed to analyze the participation of Veja magazine in the process of diffusion of neoliberal ideology in Brazil. The proposed time cut emphasized the last year of the 1980 s, a period that included the electoral campaign that marked the return of direct elections to the presidency of the Republic, won by candidate Fernando Collor de Mello. It was hypothesized that the magazine Veja had a role

pective was adopted to detect and analyze the representations built on neoliberalism at a time when this was much more a promise than a reality in the country. The research method was based on the analysis of the discourse, with the emphasis placed on published articles, published articles and interviews, and when relevant, also on reports about other countries where neoliberalism prevailed.
\end{abstract} of diffusion of this ideology, and to that end a pers-

Keywords: neoliberalism; Veja magazine; history.

Data de submissão: 2017-02-05. Data de aprovação: 2017-05-04.

A Revista Estudos em Comunicação é financiada por Fundos FEDER através do Programa Operacional Factores de Competitividade - COMPETE e por Fundos Nacionais através da FCT - Fundação para a Ciência e a Tecnologia no âmbito do projeto Comunicação, Filosofia e Humanidades (LabCom.IFP) UID/CCI/00661/2013.
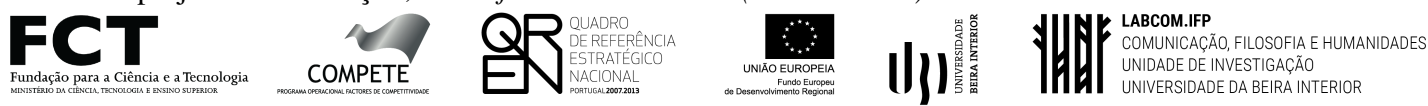


\section{INTRODUÇão}

$\mathrm{O}$

neoliberalismo, também conhecido como liberalismo neoclássico, refere-se ao ressurgimen-

to, mas com uma nova roupagem, do liberalismo econômico vigente no século XIX. De acordo com a Enciclopédia latino-americana dos direitos humanos, lançada no ano de 2016, as principais características do neoliberalismo são aquelas que sacralizam o sistema e o ordenamento capitalista: "mercado auto-regulável e livre empresa; cortes sociais, salariais e do gasto público; privatizações radicais e acumulação unilateral de bens; devastação populacional e do meio ambiente"; por outro lado, o contrario sensu dessa plataforma repudia: "economia planificada e o Estado regulador ou providente; democracias plebiscitárias, movimentos civis e de governos populares legitimados na urna; legislação laboral e redistribuição de renda; respeito à natureza e seus recursos" (Biagini, 2016, p. 533).

No cenário europeu, a emergência do neoliberalismo foi um fenômeno que ficou evidente a partir da eleição, em 1979, de Margareth Thatcher na Inglaterra e, um ano depois, de Ronald Reagan nos Estados Unidos. Tal aliança anglo-americana foi uma peça fundamental para o desmonte do Estado de Bem-Estar Social, marcando uma onda de "direitização" que percorreu grande parte do mundo, mas com raras exceções nos países escandinavos (Judt, 2011).

De acordo com o cientista político Andrew Heywood, o neoliberalismo fez parte de um projeto ideológico mais amplo da nova direita e que visou unir a economia do laissez-faire a uma filosofia social essencialmente conservadora (2010, p. 63). O historiador Tony Judt explica a mudança no imaginário social do período da seguinte forma,

No decorrer do último terço do século, porém, tornou-se cada vez mais comum deixar de tratar o Estado como o distribuidor natural dos bens coletivos e vê-lo como fonte de ineficiência econômica e intrusão social, sendo melhor excluí-lo dos assuntos dos cidadãos sempre que possível. Em conjunção com a queda do comunismo, a redução do Estado se tornou condição padrão do discurso em grande parte do mundo desenvolvido (Judt, 2010, p. 21).

O neoliberalismo apresenta como marco fundador o livro "O Caminho da Servidão", de Friedrich Hayek, escrito em 1944. Hayek o concebeu como uma crítica a planificação centralizada da economia e a intervenção política de um modo geral.

O fato é que esse ideólogo acreditava que a Social-Democracia levaria os indivíduos a um estado de servidão obrigatória. Assim, quando em 1947 são lançadas as bases do Estado de BemEstar Social na Europa, Hayek organizou, neste mesmo ano, uma reunião na estação de Mont Pèlerin, na Suíça. Surgia assim a chamada Sociedade de Mont Pèlerin, composta por Milton Friedman, Karl Popper, Lionel Robbins, Ludwing von Misses, Walter Eupken, Walter Lippman, Michael Polanyi, Salvador de Madariaga, entre outros. Seus membros passaram a se reunir a cada dois anos, sendo seu propósito maior pensar e projetar outro tipo de capitalismo que acreditavam possível, isto é, para além das amarras do pensamento keynesiano até então predominante (Anderson, 2010).

No Brasil, o neoliberalismo foi acolhido primeiramente pelo presidente Fernando Collor de Mello (na época no PRN), mas foi com os dois mandatos do presidente Fernando Henrique Cardoso (PSDB) que seu receituário foi aplicado de forma mais efetiva, o qual foi expresso, por exemplo, na privatização de um grande número de empresas públicas. 
Os méritos da gestão de Cardoso ${ }^{1}$ são geralmente diagnosticados pelo sucesso do Plano Real. Este plano, elaborado ainda durante o governo de Itamar Franco ${ }^{2}$, "catapultou a candidatura de Fernando Henrique Cardoso à Presidência da República" (Fico, 2015, p. 131) e, de fato, obteve êxito por amenizar a inflação crônica, o que acabou por beneficiar os segmentos de menor poder aquisitivo que não tinham como proteger seu dinheiro da desvalorização diária. Por outro lado, ao final do mandato de Cardoso o "desemprego dobrou e a concentração de renda, uma característica histórica da sociedade brasileira, continuou no mesmo patamar, o sexto mais alto do mundo" (Pilagallo, 2009, p. 87).

Além disso, as privatizações que Cardoso levou a cabo não representam um consenso, pois elas receberam inúmeras críticas de setores da academia, da esquerda, dos movimentos sociais etc. $\mathrm{O}$ jornalista Aloysio Biondi (2014), na contramão da grande imprensa brasileira na época, escreveu o livro "O Brasil privatizado: um balanço do desmonte do estado", denunciando e criticando duramente a forma como ocorreram as privatizações no Brasil. De modo semelhante, a avaliação do filósofo Guilherme Boulos é a de que a privatização "da Vale, da Telebrás e do setor elétrico foi um crime de lesa-pátria e levou a perdas financeiras inestimáveis" (Boulos, 2016, p. 112).

Se o neoliberalismo no Brasil teve essa ancoragem a partir de Collor (1990 - 1992), avançando sobremaneira com Cardoso (1995 - 2002), nosso intuito neste artigo foi o de investigar como, num período anterior a sua práxis $^{3}$, estava se comportando a mídia impressa brasileira, em particular, a revista Veja. Deste modo, este artigo teve por objetivo avaliar uma possível participação dessa mídia no processo de difusão da ideologia neoliberal no Brasil. O recorte temporal proposto enfatizou o último ano da década de 1980, período que compreende a campanha eleitoral que marcou o retorno das eleições diretas para a presidência da República, vencida - com apoio da grande mídia, em especial da Rede Globo - pelo candidato Fernando Collor de Mello.

Partiu-se da hipótese que a revista Veja poderia ter desempenhado um papel de difusão dessa ideologia. Para tanto, se adotou uma perspectiva de detectar e analisar as representações construídas sobre o neoliberalismo num momento em que esse se constituía muito mais em uma promessa do que uma realidade no país. O método de pesquisa ocorreu por meio da análise do discurso, sendo realizada a leitura das 50 edições da revista Veja publicadas ao longo do ano de 1989, com especial atenção aos editoriais, matérias e reportagens que abordavam o assunto. Como já mencionado, a escolha desse ano se deveu em função das eleições diretas, e eleições que eliminaram da década seguinte dois projetos intervencionistas e mais preocupados com a questão social - no caso, Lula (PT) e Brizola (PDT) - e legitimaram a onda neoliberal que se instalou no país durante toda a década de 1990.

1. De primeiro de janeiro de 1995 a 31 de dezembro de 2002 .

2. De 29 de dezembro de 1992 a primeiro de janeiro de 1995 .

3. Utilizamos o termo aqui do modo irônico e com o sentido contra-revolucionário, pois como se sabe o conceito de práxis está ligado à obra de Karl Marx, que o define nas "Teses sobre Feuerbach" (1845) como atividade objetiva e efetiva, ligada a transformação social e a ação revolucionária dos trabalhadores. 


\section{Material e Métodos}

\subsection{A revista Veja}

A revista Veja foi lançada pela editora Abril no ano de 1968, e isso numa iniciativa de Roberto Civita, filho de Victor Civita, então proprietário da editora Abril. Vale destacarmos que no início essa revista contou também com o jornalista ítalo-brasileiro Mino Carta como diretor de redação (desde 1994, Mino Carta é editor da revista Carta Capital, tida como de uma linha editorial oposta a da revista $V e j a)$.

Embora a editora Abril tenha recorrido a uma ampla campanha para o lançamento de Veja no ano de 1968, a publicação só obteve sucesso de vendas após seis anos no mercado. O início difícil pode ser explicado tanto pelo momento histórico que passava o país, marcado pelo aumento no número de televisores (Abreu, 2002, p. 19), quanto pelo formato da própria publicação, diagramada com mais texto do que imagens, aspecto esse que não era conhecido do público brasileiro à época. No entanto, após a persistência de Roberto Civita em manter a revista em circulação e uma campanha de assinaturas exitosa, a revista que não tinha futuro tornou-se bastante promissora (Corrêa, 2012, p.221).

Aos poucos, Veja se transformou na revista mais vendida do Brasil. Em estudo realizado pela pesquisadora Maria Celeste Mira, foi constatado que Veja chegou ao ano de $1988 \mathrm{com}$ a tiragem de 800 mil exemplares, tornando-se a quinta maior revista semanal de informação do mundo. Além disso, nesse mesmo ano ela foi considerada a $5^{\mathrm{a}}$ maior do mundo em circulação e a $3^{\mathrm{a}}$ em páginas de publicidade, perdendo somente para Time e para a italiana Panorama (Mira, 2001, p. 94).

Assim, dado sua trajetória de proeminência na formação da opinião pública, a revista Veja pode ser considerada uma valiosa fonte para pesquisas históricas, e em especial para pesquisas ligadas a chamada História do Tempo Presente, isto é, para a produção de um tipo de história mais preocupada com o tempo próximo do que com o tempo distante.

Mas é importante lembrarmos, entretanto, de que independente desse trabalho com uma temporalidade mais próxima, a função do historiador presenteísta se diferencia tanto da função do jornalista, que usualmente escreve sobre o aqui-agora, quanto da prática antropológica, a qual, segundo Marc Augé, interessa-se pela interpretação do "outro" e o estuda através do trabalho de campo (1994, p. 14). Assim, como sustentam os historiadores Agnès Chauveau e Philippe Tétart (1997), trabalhar com a chamada "História do Tempo Presente" não significa isolar os objetos ou abordar apenas o instante, mas sim lidar com o tempo e inscrever a operação historiográfica na duração que o objeto de pesquisa solicita. Neste sentido, o principal objetivo dos historiadores presenteístas seria o de oferecer, mesmo de forma provisória, uma primeira base explicativa para fenômenos ainda não devidamente historicizados ou incorporados no campo da história contemporânea.

\subsection{Método da análise}

Ao longo do ano de 2016 foi realizado o levantamento no arquivo digital da revista Veja http://veja.abril.com.br/acervodigital/home.aspx -, das publicações referentes ao ano de 1989. To- 
das as edições deste ano foram verificadas, o que contabilizou um total de 50 edições, sendo a primeira edição a de número 1061, de 04/01/1989, e a última a edição 1111, de 31/12/1989.

Para atender os objetivos dessa pesquisa, o método de análise do discurso adotado encontrou sua inspiração em Foucault, e isso se deveu, em larga medida, pela "importância que ele atribuiu à linguagem/discurso enquanto meio de apreender as transformações" (Eizirik, 2005, p. 91). Assumir esse procedimento metodológico implicou afirmar, fundamentalmente, que tivemos por objetivo estudar os mecanismos que permitiram a hegemonia ou dominação de um discurso; ou, em outros termos, o poder de um discurso sobre os outros (Chizzoti, 2010, p. 124). Para Foucault, o poder de um discurso pode colocar em funcionamento mecanismos de organização do real através da produção de determinados saberes e da ocultação de outros. Deste modo, como escreveu Judith Revel, "a arqueologia foucaultiana dos discursos não é apenas uma análise lingüística, mas uma interrogação sobre as condições de emergência de dispositivos discursivos que sustentam práticas" (Revel, 2005, p. 38). Assim, a análise discursiva da revista Veja foi realizada levando em consideração as condições históricas, econômicas e políticas do período.

Partimos do pressuposto de que é praticamente impossível compreender a história recente do país sem levar em consideração o papel dos meios de comunicação de massa, pois tais meios têm uma influência muito grande na produção da chamada "opinião pública". Deste modo, as revistas impressas - como é o caso de Veja - não só podem como devem integrar o acervo de documentos do historiador contemporâneo tal como assevera o pesquisador Luís Felipe Miguel:

As revistas se propõem a apresentar uma narrativa da história do tempo presente, de maneira ainda mais ostensiva do que o jornalismo diário, justamente pelo caráter de síntese interpretativa de que se reveste seu material. Ao mesmo tempo, são - como toda mídia - agentes num campo de disputas, cujas estratégias precisam ser analisadas como tal. Por fim, transformamse em fontes para o estudo posterior dos acontecimentos que narram, mas, sempre, fontes situadas e interessadas, aspecto que a pesquisa histórica não pode deixar de lado (Miguel, 2016, p. 10).

Deste modo, o trabalho do historiador com a imprensa pode e deve atinar-se para o papel que essa desempenha na construção discursiva sobre os fatos, levando em conta que nenhum registro é ingênuo ou descompromissado, uma vez que todos pressupõem o trabalho com a linguagem e uma tomada de posição do sujeito que o faz (Ribeiro, 2005, p. 120). Deste modo, cabe aos historiadores também considerar como um plano de análise aquilo que o sociólogo Pierre Bourdieu chamou de análise exógena ao discurso. Para avaliarmos o poder das palavras, é necessário sabermos quem estão proferindo-as, uma vez que a forma e o conteúdo do discurso resultam da posição social - e também ideológica - de quem o profere. Em outros termos, um discurso é autorizado na medida em que o agente tem legitimidade para tanto. O poder das palavras emana tanto da condição social e simbólica do seu proferidor como também de sua condição de detentor do capital social que algum grupo outorgou-lhe legitimidade (Bourdieu, 1996).

Ao partirmos do pressuposto de que as publicações não funcionam somente como um espelho social (Cruz, 2007, p. 259), a investigação atinou para o possível papel que Veja exerceu na articulação e divulgação de ideias e valores relacionados ao neoliberalismo. 


\section{Resultados e Discussão}

Em função dos limites de escrita de um artigo (diferente dos limites de um livro, por exemplo), não iremos comentar aqui todas as 50 edições da revista Veja analisadas, mas apenas algumas daquelas que mais nos chamaram à atenção. Levamos em consideração, na medida do possível, a ordem cronológica das publicações, apresentando inicialmente o lugar que Veja fornecia às vozes que sustentavam uma crítica ao Estado brasileiro, passando por sua adesão ao pensamento de Margareth Thatcher e finalizando o artigo com a posição assumida pelo editor de Veja no debate presidencial entre os candidatos Lula e Collor.

Assim, a primeira edição que abordamos aqui data de 25 de janeiro de 1989, e em especial destacamos a sessão "Ponto de Vista", escrita por Roberto Demeterco, dono da rede de supermercados Mercadorama e vice-presidente da Associação Brasileira de Supermercados. Sua função foi a de apresentar "soluções" para o desenvolvimento econômico do país. Partindo deste pressuposto, Demeterco defendeu que apenas ampliando a liberdade do indivíduo e diminuindo a influência do Estado sobre a vida da população seria possível chegarmos ao crescimento e ao desenvolvimento. Demeterco enfatizou os benefícios do livre mercado e os ganhos que poderiam ser trazidos à população com base na livre concorrência e a redução do papel do Estado na sociedade.

Além disso, esse senhor dividiu a população brasileira em dois grupos: os de lá, formados por políticos (honestos e corruptos), beneficiados por bons cargos, agraciados por regalias e pagos por bons salários; e os de cá, formados pela população em geral, ou seja, por trabalhadores mal remunerados devido às restrições impostas pelo Estado e, consequentemente, totalmente vulneráveis às suas decisões.

Seguindo esse raciocínio, Demeterco destacou a importância da mobilização das mídias e da população para um embate a essa situação pela qual estaríamos então submetidos. De forma conclusiva, Roberto Demeterco afirmou que a "doença brasileira é a ausência de uma doutrina liberal onde a sociedade se reestruture e tenhamos um só Brasil" (p. 114). Por fim, ele defendeu que com a aplicação do liberalismo no país, o Brasil se igualaria - num prazo de 10 anos - a países europeus e aos Estados Unidos.

Interessante destacarmos que na edição de 08 de fevereiro de 1989, na sessão de cartas dos leitores - chamada de "Livre Iniciativa" -, o leitor Antonino Mascarenhas escreveu para a redação da Veja com o intuito de apoiar as palavras de Demeterco. Segundo esse leitor, o pensamento de Demeterco reflete exatamente o pensamento da maioria dos brasileiros, mas o governo não dá atenção aos ideais da população.

$\mathrm{O}$ apoio as privatizações (que seriam realizadas posteriormente pelos presidentes Collor e, sobretudo, por Fernando Henrique Cardoso) também recebeu destaque na revista neste ano de 1989. Na edição de 22 de março, por exemplo, numa entrevista com Márcio Fortes, então presidente do BNDES, foi destacado que a privatização de certas empresas do Estado seria um fator de grande relevância para a economia nacional (p. 5).

O então presidente do BNDES também apontou a importância da privatização com o intuito de arrecadar lucros para o país. Nesta entrevista, foi destacado o seu interesse em privatizar estatais para instituições estrangeiras com o intuito de melhorar as relações exteriores. Na visão de Fortes, 
seria apenas uma questão de tempo para que tais privatizações viessem a ser uma possibilidade concreta.

Para exemplificar e reforçar as suas propostas, ele comentou as perspectivas e alternativas de privatização das siderúrgicas no Estado do Rio de Janeiro (p. 6). Contudo, no embasamento desta argumentação, na última página da entrevista, foi mencionado o documento "Estado da Economia Brasileira até o Ano 2000", e isso com o objetivo de reforçar a tese de que o setor público brasileiro vinha passando por uma crise que, apesar de conjuntural, seria de longa duração (p. 8). Seguindo nesta linha, foi trazido à tona por Márcio Fortes um plano que possibilitaria as privatizações num futuro próximo, mais precisamente, estabelecendo como meta final a década de 2000. Em síntese, afirmou-se que, por meio destas privatizações, estaríamos livres da dívida externa, além de qualificarmos os serviços voltados à população.

Em grande parte, a exaltação do liberalismo em Veja se dava pela grande quantidade de matérias publicadas com críticas ao socialismo nos países do Leste Europeu e na URSS. Neste sentido, por exemplo, numa matéria intitulada "Rivalidades Fatais: Tensões regionais e uma economia em pane se somam para sacudir o socialismo na Iugoslávia”, a revista Veja, em sua edição de 05 de abril de 1989, comentava que o modelo ideal de governante para a Iugoslávia seria a neoliberal Margareth Thatcher (então primeira-ministra da Grã-Bretanha), defendendo também a abertura de mercado para o país, indicando que tal medida seria percebida por todos os moradores da Iugoslávia como sendo um grande progresso (p. 50-51).

$\mathrm{O}$ apreço de Veja por Margareth Thatcher pode ser verificado também em outras reportagens do ano de 1989. Numa edição de 02 de agosto, por exemplo, mesmo apontando as divergências da população da Grã-Bretanha diante do aumento das privatizações do setor público, Veja destacou que as medidas tomadas por Margareth Thatcher tinham o intuito de combater a inflação no país, que já chegava a 8,6\% ao ano. Ao final da matéria, Veja fez um balanço dos dez anos de mandato de Thatcher, ressaltando os diversos êxitos de sua gestão.

O enaltecimento de Thatcher marcava, portanto, o apreço dessa revista pelos ideais neoliberais. Em edição publicada no dia 31 de dezembro de 1989, numa matéria de título sugestivo: "Anos 80: A poesia do dinheiro: Ser rico virou motivo de projeção e valorização social nos anos 80. Ficou para trás os tempos em que os milionários eram chamados de tubarões. Magnatas como Iacocca, Forbes e Trump deram o tom da década", a revista mais uma vez tece elogios à gestão de Thatcher. Além disso, na reportagem citada, foram destacados os sucessos desses empresários milionários que obtiveram grande crescimento de suas finanças durante a década de 1980, relacionando o aumento de suas riquezas com o aumento da popularidade. Ao mesmo passo, Veja enfatizava as posturas neoliberais de determinados políticos, como era o caso do então presidente estadunidense Ronald Reagan e da primeira ministra inglesa Margareth Thatcher (uma imagem dela comemorando abre esta reportagem), apontando seus grandes êxitos e conquistas no decorrer dos anos. Especialmente no caso de Thatcher, a revista aponta os pontos de relativo sucesso em seu governo, escrevendo que,

A primeira-ministra britânica atravessou a década desafiando algumas das mais arraigadas tradições inglesas - todas do trabalhismo - e desfraldando a bandeira do liberalismo econômico levado a outrance. Em três mandatos sucessivos, a dama de ferro enfrentou e derrotou greves, fez os sindicatos abaixarem a crista, cortou subsídios sociais e privatizou estatais a granel. 
Com isso, Thatcher sacudiu a Inglaterra e colocou a economia do país em marcha depois de anos de pasmaceira e estagnação (Veja, 31 de dezembro de 1989, p. 147).

Ao verificarmos esse discurso da revista, em que apenas enalteceram as vitórias da primeira ministra, sentimos falta de um posicionamento crítico deste periódico, pois a crescente impopularidade da "dama de ferro" diante da população inglesa não ocorria, obviamente, pelos seus êxitos ${ }^{4}$. Assim, o fato é que Veja poderia ter apontado as consequências das medidas tomadas, e assim, demonstrar maior cuidado com os dados transmitidos aos leitores/as do periódico. Ao desprezas as críticas em nome de um enaltecimento da primeira-ministra, Veja assumia um claro viés ideológico e político.

Ao longo do ano de 1989, foram diversas as manifestações contidas nessa revista a favor do crescimento do setor privado e da diminuição do setor público. Na sessão "Ponto de Vista" publicada na edição de 19 de julho, a revista trouxe a opinião do leitor Mauricio Ferreira Lima, o qual relatou sua indignação com o funcionamento do serviço público no país. Através de uma comparação com os empreendimentos privados, ele elaborou sua argumentação apontando que o Estado possui grande quantidade de empregados em distintas funções, mas em diversos casos esse excedente de funcionários não se faz necessário. Por conseguinte, também destaca que necessitamos de presidenciáveis dispostos a diminuir o contingente de contratados no serviço público, com o intuito de resgatar a "máquina governamental do fracasso" (p. 118).

Essa perspectiva neoliberal de Veja, já em 1989, pode ser percebida também na publicação de matérias que exaltavam e apoiavam a vinda de empresas multinacionais para o Brasil. Numa matéria intitulada: "Economia \& Negócios: Sinais de Progresso: O balanço de Melhores e Maiores mostra que as empresas privadas cresceram em 1988 e têm reservas, enquanto as estatais vão mal", e publicada em 23 de agosto, Veja destacava que o crescimento de empresas privadas no país foi 3,7\% em 1988 (p. 98)., indicando que esse crescimento estava atrelado à desvinculação do poder do Estado, ou seja, ao afastamento das limitações impostas por órgãos reguladores (p. 99).

Nas páginas seguintes dessa edição, após destacar os pontos negativos e as crises pelas quais as empresas estatais estariam inseridas entre 1988 a 1989, Veja ressaltava os benefícios que as multinacionais poderiam trazer ao Brasil. Partindo deste ponto, também indicava que se tratava de uma falácia a ideia de que as multinacionais que se instalam em países subdesenvolvidos somente têm interesses na exploração destes. A revista sugere, deste modo, que a vinda de multinacionais ao Brasil estaria ligada a uma maior abertura do mercado e que isso geraria um maior desenvolvimento e crescimento econômico (p. 100).

Essa exaltação das multinacionais também foi exposta numa publicação de 27 de setembro, quando a revista apresentou em suas páginas uma propaganda de uma empresa multinacional da Alemanha que obteve sucesso no Brasil, sendo essa intitulada: "Voith: há 25 anos era apenas capital alemão, hoje é lucro brasileiro". Nesse anúncio são apresentados os fatores atrelados à rentabilidade desta indústria em território nacional, além da indicação de seus principais pontos de participação na economia do país, seja nos equipamentos que "correspondem a de $40 \%$ da

4. Em vídeos disponibilizados pelo youtube, por exemplo, indicamos um que demonstra a torcida de Liverpool comemorando a morte de Margareth Thatcher, pois essa desagradou os trabalhadores ao reprimir movimentos sociais. O vídeo está disponível em: www.youtube.com/watch?v=gyW3IbS1cTY, acesso em 01/02/2017. 
capacidade de geração de energia elétrica", ou mesmo, na produção em $50 \%$ da produção de papel. Em distintos pontos Veja transmite ao leitor a idéia de que a Voith foi uma empresa que se arriscou ao investir seu capital no Brasil, dado o país estar passando por crises e problemas com inflação. Em seguida, ela aponta que o investimento de capital estrangeiro desta empresa, ou mesmo de outras indústrias que aqui se encontram, só trouxeram vantagens à população, seja através de empregos, fornecimento de produtos de qualidade ou no pagamento de impostos ao país (p. 19).

Incitar a vinda de multinacionais ao país era um ponto que caracterizava o espaço que Veja fornecia ao discurso neoliberal. Ainda em sua edição de 27 de setembro, as empresas japonesas também foram requeridas. Num texto de autoria de Mario Augusto Costa Azevedo, engenheiro e dono de uma empresa de autopeças em Belo Horizonte, também escrito para a sessão "Ponto de Vista", foi possível verificarmos a sua defesa pela abertura do mercado nacional para as montadoras japonesas. Para tanto, ele defendia que países europeus e os Estados Unidos qualificaram a sua produção de veículos a partir da instalação de empresas japonesas, pois apesar da inferioridade de seus carros, seus preços eram mais acessíveis e isso acabou por levar as demais montadoras a também abaixarem o custo de seus veículos em função da concorrência, fato que teria beneficiado os consumidores, explica.

Desta forma, Azevedo indica que a abertura do mercado seria mais proveitosa para a fabricação de veículos do que a regulação feita pelo Estado a partir de altas taxas tributárias. Segundo o autor, a partir da concorrência advinda do livre mercado, poderíamos obter até mesmo uma maior qualidade de veículos produzidos no país (p. 170).

Essa crítica ao governo em contraste com a iniciativa privada e a livre concorrência ganhou fôlego na entrevista que Veja realizou com o empresário gaúcho Cézar Rogério Vicente, publicada em sua edição de 04 de outubro de 1989. Cézar Vicente, então dono do Grupo Central e presidente da Confederação das Associações Comerciais do Brasil, fez ampla defesa do liberalismo em sua esfera econômica. No decorrer dessa entrevista, Vicente defendeu a classe empresarial, apontando que as acusações referentes a eles diante da inflação e da crise financeira do país são equivocadas. Desta forma, desferiu diversas acusações à má administração do governo diante de suas finanças, além dos inúmeros problemas das empresas estatais em relação à sua produção. Partindo deste ponto, também indicou sua reprovação ao mandato de José Sarney, relatando que a Confederação das Associações Comerciais do Brasil não dialoga com o presidente a respeito de possíveis melhorias econômicas para as indústrias brasileiras. Sendo assim, colocou que só abririam novos debates durante a próxima gestão, quando outro presidente fosse eleito.

Com relação às intervenções estatais na iniciativa privada, como é o caso do ajuste do salário mínimo, Vicente se opôs a tal medida, pois a considera prejudicial à iniciativa do livre-mercado e limitadora do crescimento das empresas (p. 7). Em certos trechos deste diálogo, o empresário demonstrou certa aversão ao PT ao apontar que não dialogara com o prefeito de Porto Alegre (eleito pelo Partido dos Trabalhadores), pois divergiam em diversas questões ideológicas.

Com a proximidade das campanhas eleitorais para a escolha do primeiro presidente eleito pelo voto popular após o processo de redemocratização do país, as matérias de Veja concentram-se mais propriamente nesse assunto. $\mathrm{O}$ que notamos, e isso sem grandes dificuldades, foi o viés da 
revista contra os candidatos da esquerda (contra o PT em particular) e um elogio à candidatura de Fernando Collor de Mello ${ }^{5}$.

Numa matéria intitulada "Lula e a propriedade: O PT começa a debater o seu plano de governo, enfrenta divergências internas e dá força à máquina estatal", publicada em sua edição 26 de abril, a revista, após tratar das questões partidárias levantadas nas eleições presidenciais, apontava já o favoritismo crescente de Fernando Collor (p. 47) e também questionava os planos do PT atrelados ao futuro da "economia liberal" no Brasil (p. 51). Veja destacou que esse partido teria fortes interesses em realizar uma reforma agrária, desapropriando terras produtivas e improdutivas no país. Desta forma, a revista advertia ao leitor que os objetivos do PT seriam o de aumentar os impostos sobre as grandes fortunas e criar taxas para doações e heranças. Além disso, Veja também afirmava que os objetivos do Partido dos Trabalhadores seriam o de ampliar o poder do Estado com a criação de uma emissora de televisão que consiga alcance nacional, acabando com os monopólios do setor, além de realizar a estatização dos setores da saúde e educação e, posteriormente, do sistema financeiro.

No dia 01 de novembro de 1989, já às vésperas das eleições presidenciais, Veja publicou sua edição de n. 1103, na qual continha a matéria: "PT no moedor de carne: Lula cresce e adversários preparam a carnificina para a reta final". Esta reportagem foi pautada em apresentar as acusações e defesas relacionadas ao candidato Lula durante sua reta final para as eleições de novembro de 1989. Dentre as denúncias, podemos citar a de Ronaldo Caiado (PSD), que afirmava que o presidenciável petista usou dinheiro de propinas oriundo de empreiteiras. Em sua defesa, conforme fora destacado pela revista, Lula afirmou que "na Justiça provaremos que essa acusação é leviana". Já no segundo tópico da matéria, sob o título "Sarney e a Constituição", a revista trouxe à tona o posicionamento de outros políticos sobre Lula, os quais o consideravam um grande risco para o país, como foi o caso do depoimento de Ricardo Friuza (PFL-PE). Esse político afirmou que, caso Lula ascendesse à presidência, seria recebido no "Congresso com uma emenda criando o regime parlamentarista", e concluía: "Lula é um homem primitivo e não tem condições de governar" (p. 49).

Veja trazia muitos nomes, de empresários, políticos e de seus próprios leitores preocupados em tecer críticas a Lula e a seu projeto de governo. O periódico chegou a entrevistar o próprio concorrente direto de Lula nas eleições, o presidenciável Fernando Collor de Mello, que mirou suas críticas no candidato petista. Assim, em matéria publicada no dia 22 de novembro, já durante o segundo turno das eleições, Collor declarava que não faria alianças com partidos políticos, pois era contra esta postura. Além disto, a certa altura, ele apontava que na Europa "ninguém mais fala

5. Ao longo da campanha presidencial, a revista Veja deixou claro seu favoritismo pela candidatura de Fernando Collor de Mello, e em especial durante o segundo turno das eleições. Tal fato pode ser visto, por exemplo, na matéria: "PRN - Na porta de entrada: chega à reta final o candidato Collor de Mello, que parecia sem chances no início da campanha e que se tornou o fenômeno da temporada", publicada numa edição especial sobre as eleições na data de 15 de novembro de 1989. Já em sua edição de 06 de dezembro de 1989, Veja apontava que o proprietário da mais potente rede de televisão do país, o empresário Roberto Marinho, também apoiava Collor (p. 49). No universo acadêmico, o modo como a revista Veja apoiou o candidato Collor foi analisado em estudo publicado em 2015 pelos historiadores Alan Mengarda e Leonardo Brandão, no volume 8 da Revista Recorde (UFRJ). Nesse estudo em especial foi notado como Veja exaltou a candidatura de Collor ao associar sua imagem a de um esportista, cheio de saúde e vigor. 
em direita e esquerda, apenas na diminuição da máquina do Estado e no bem-estar da população, independentemente da posição ideológica" (p. 69).

No diálogo com o entrevistador, Collor também afirmava que Lula não foi tão bem votado nas cidades onde o PT governa, pois, os eleitores que conheciam a administração do partido não repetiriam o voto (p. 68). Por fim, em diferentes pontos da entrevista, destaca o radicalismo de candidatos de partidos de esquerda, traçando assim a diferenciação dele diante de Lula, especialmente em relação à máquina estatal, a qual ele defendia o enxugamento enquanto os petistas prefeririam o "fortalecimento do Estado, a estatização e a socialização do país". Além disso, o candidato do PRN salientava que "há correntes do PT que pensam que não se chega ao poder sem revolução sangrenta" (p. 68).

Assim, ao insistir em dar voz aqueles que diferenciavam Collor de Lula - inclusive para o próprio Collor -, a revista Veja fazia, através dessa estratégia, sua aposta no liberalismo como uma solução para os problemas do país. Na edição de 13 de dezembro de 1989, a revista trazia como manchete de capa: "A batalha final para mudar o Brasil: o que pode ocorrer no país com Lula ou com Collor".

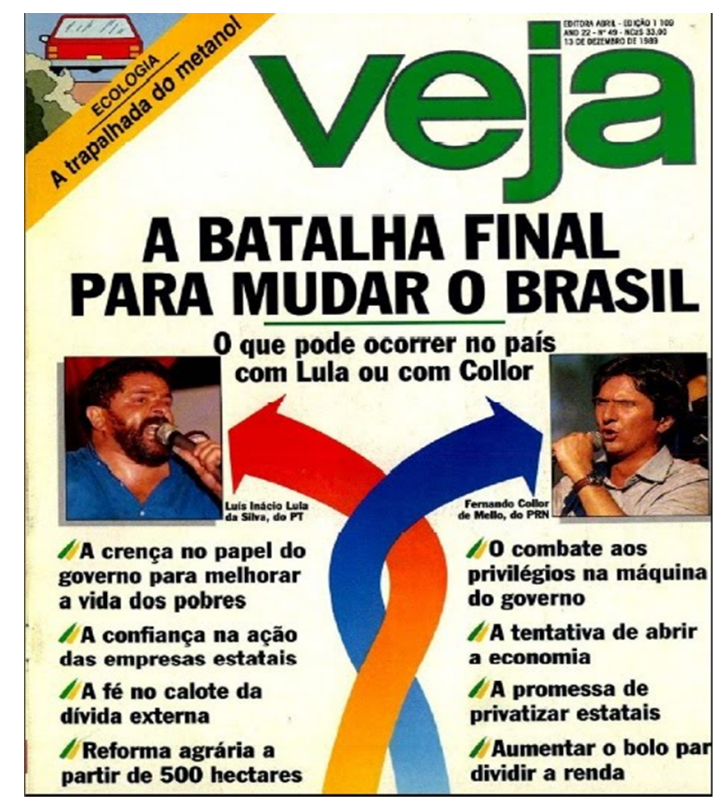

Figura 1. Capa da Revista Veja, edição 1109, de 13 de dezembro de 1989.

Interessante notarmos que Veja se valia dessa capa para diferenciar os dois candidatos, pois na capa havia um breve resumo das propostas de ambos os candidatos. Como podemos observar na imagem acima, constava na capa a foto de ambos os presidenciáveis, tendo seus planos de governo resumidos. No lado de Lula (PT) constava que esse tinha "A crença no papel do governo para melhorar a vida dos pobres", enquanto no lado de Collor (PRN) constava que ele trabalharia no "combate aos privilégios na máquina do governo". Além disso, enquanto Lula tinha "A con- 
fiança nas empresas estatais", Collor tomava por objetivo "A tentativa de abrir a economia (fato que vinha sendo ressaltado insistentemente por Veja como a melhor solução para os problemas econômicos do país ao longo de suas edições passadas). Por fim, a própria matéria de capa também destacava que Lula tinha "A fé no calote da dívida externa", ao passo que Collor fazia "A promessa de privatizar estatais" (outro aspecto que foi destacado como eficaz alternativa para o desenvolvimento do país ao longo de diversas edições deste periódico).

É preciso reconhecer que Veja era coerente com o que defendia. Ela não mentia ao seu leitor, mas sim acreditava no liberalismo como uma solução para os problemas econômicos do país. Entretanto, ao tomar lado por uma causa, Veja se posicionava claramente à direita e contra a esquerda. De fato, ela chega a assumir esse posicionamento editorial realizado às vésperas do segundo turno. O editorial era endereçado aos seus leitores, com o título: "Carta ao leitor: democracia avançada e miséria social" (Veja, 13 de dezembro de 1989).

Neste editorial, pela primeira vez o periódico assume com todas as letras a sua postura de defensor de ideais liberais, tanto nos aspectos econômicos quanto políticos, diante das eleições presidenciais de 1989. Apesar de em outras ocasiões também apoiar posturas atreladas ao liberalismo, em especial a abertura de mercado e a privatização de empresas estatais, ou seja, se colocando favorável à diminuição da presença do Estado; nesta ocasião, isto fica explícito. Acima de tudo, Veja destaca que haverá uma cobrança, após os resultados das urnas por parte da revista, e cobranças para que o presidente eleito cumpra suas promessas e atenda aos interesses que defende (evidentemente, Veja diz isso para Collor, porque tudo indica que jamais cobraria de Lula que fizesse a Reforma Agrária, por exemplo).

Desta forma, importante observar alguns trechos dessa Carta ao Leitor, para reforçarmos o que argumento acima. No início do segundo parágrafo, encontra-se escrito que "tanto Fernando Collor de Mello quanto Luís Inácio Lula da Silva prometem derrubar o muro de vergonhas que separa a maioria dos brasileiros das condições mínimas de levar uma vida decente". A partir destas considerações trazidas à tona, portanto, Veja entra no ponto central dessa explanação, conforme podemos verificar a seguir: "A questão é como acabar com esse muro - e os candidatos apresentam respostas bem diferentes". Por fim, a revista assume com todas as letras sua postura política e ideológica, como podemos conferir a seguir:

Veja considera que não será com estatização e com cerceamento à livre iniciativa, com o incremento de conflitos entre o capital e trabalho, com restrições aos investimentos, com o isolamento do mundo desenvolvido e com o nivelamento por baixo que o país irá melhorar. A revista defende, desde a sua fundação, e reafirma nesta véspera de eleição, que o caminho para melhorar as condições de vida dos brasileiros é a liberdade política e econômica [...] (Revista Veja, 13 de dezembro de 1989, p. 42).

As considerações até aqui assinaladas demonstram o posicionamento da revista diante das eleições presidenciais de 1989. Sem muito esforço podemos identificar o apoio a Collor e o repúdio às posturas de Lula, no qual o primeiro é associado a medidas mais voltadas ao suporte do mercado enquanto o segundo é taxado como alguém ligado a um projeto de estatização e fortalecimento do Estado.

Para finalizar, mas ainda no tocante as eleições presidenciais, um ponto alto na defesa do liberalismo foi a entrevista que a revista Veja fez com o senador Roberto Campos, publicada em 
sua edição de 21 de junho de 1989. Intitulada: "Um país fora de moda. Entediado com as idéias dos oponentes, o senador Roberto Campos cobra uma receita econômica dos presidenciáveis e dá a saída para a crise". Nessa entrevista, Roberto Campos deixa claro, ao responder perguntas a respeito das medidas econômicas para o crescimento do país, que as propostas que fortaleçam a participação do Brasil no mercado externo (com a abertura para instalação de empresas no país) seriam as mais indicadas. Portanto, ele declara que para existir de fato um desenvolvimento econômico seria necessário um "casamento da democracia política e a economia de mercado, isso que se chama de neoliberalismo" (p.5).

Campos também destacou nessa entrevista que o Brasil se encontrava em atraso se comparado a outras nações, especialmente por restringir o investimento de capital estrangeiro. Além disso, indica que no país não existe capitalismo, especialmente por não contemplar os três pressupostos para a sua existência: "liberdade de acesso ao mercado, sistema de preços e regras estáveis de direito" (p.6). Ao concluir sua argumentação, ele afirma que apesar do país ter conquistado a liberdade democrática, ele ainda não havia alcançado a liberdade econômica.

Essa entrevista com Roberto Campos foi elogiada em carta escrita pelo leitor Danilo Farias (Fortaleza - CE) em edição publicada no dia 05 de julho. O leitor escreve para a Veja agradecendo pela entrevista, enaltecendo a publicação da mesma num período próximo às eleições, pois "se os políticos não tivessem cometido os erros apontados pelo brilhante senador, nosso país não estaria na situação em que se encontra" (p. 13).

Similar a essa entrevista com Campos, foi a entrevista que Veja fez com o ministro da Fazenda, Maílson da Nóbrega em sua edição de 24 de dezembro de 1989. Realizada pela jornalista Rita Medeiros, nessa entrevista podemos verificar que as perguntas direcionadas a Nóbrega, nas vésperas do final de seu mandato, referem-se especialmente às perspectivas dele acerca do próximo mandato e das possibilidades que a partir de então poderão ser trazidas no governo do país.

Além disso, em distintos pontos deste diálogo, são feitas críticas às possibilidades de congelamento de preços e da economia brasileira. Se levarmos em conta as perguntas do periódico dirigidas ao entrevistado, poderemos verificar que se referem às dificuldades de privatização de "algumas empresas e extinguir alguns ministérios" (p. 6), devido a não aprovação do Congresso.

Por sua vez, o ministro indicou que na "classe política brasileira prevalece ainda uma cultura estatizante", e que para haver uma mudança "vamos ter de passar por um processo educativo" (p. 8). Partindo deste ponto, Maílson da Nóbrega aponta que nota "um trabalho persistente das estatais levando uma mensagem para a sociedade brasileira de que elas são indispensáveis" (p. 8). Seguindo nesta linha, ele cita o caso da conservadora Margareth Thatcher (Inglaterra) e de Felipe González (Espanha) que utilizaram a privatização para combater o "déficit e a inoperância do Estado", reforçando sua tese de que o déficit público e a privatização não são uma questão levantada por partidos de esquerda ou de direita, mas questões a serem debatidas, que neste contexto "começaram a se desligar de seu componente ideológico".

Ao final da entrevista, o ministro levanta uma proposta mais radical de privatização, pois diz: "No Brasil, privatização ainda é encarada pelo prisma ideológico, mas tenho certeza de que chegará logo o dia em que discutiremos até mesmo a privatização de símbolos como a Petrobrás e o Banco do Brasil. Por que não? (p. 8). 
O ano de 1989 chega ao fim e o novo presidente da República é eleito. O resultado do segundo turno fora comemorado na última edição analisada nesta pesquisa (edição de 31 de dezembro de 1989) em longo texto escrito por Victor Civita (seu editor e diretor). Intitulado "O desafio da nova década", o texto explica que os resultados das eleições presidenciais, elegendo Fernando Collor de Mello, "por uma ampla maioria", são uma prova de que os brasileiros escolheram o "caminho da modernidade" (p. 198). Atrelado a isso, o diretor e editor da Veja também garante aos seus leitores que, a partir deste momento, a população deve "definir os limites" e exigir "padrões de qualidade e eficiência" diante das funções desempenhadas pelo novo presidente.

\section{Considerações Finais}

Nos últimos anos há um movimento já bastante conhecido de desconfiança com a revista Veja, sobretudo por seu caráter contínuo de ataques ao PT e a esquerda de um modo geral; movimento esse que engloba também sua mídia digital e blogueiros (em especial Reinaldo Azevedo). Um dos primeiros jornalistas a denunciar isso com contundência foi Luís Nassif, que chegou a trabalhar em Veja durante 10 anos, de 1969 a 1979. Nassif, em entrevista concedida a revista Caros Amigos no ano de 2008, afirmou que em 38 anos de carreira nunca presenciou um jornalismo tão sem escrúpulos e com falta de respeito quanto o feito pela revista Veja, e isso pelo menos desde a década de 1990. Segundo ele, essa revista, quando se engajou no impeachment de Collor e foi vitoriosa, passou a tratar qualquer assunto como escândalo, pois percebeu nisso uma estratégia comercial para o aumento das vendas. Assim, embora Veja tenha caído num certo descrédito, ao ponto de Nassif afirmar que "nenhuma pessoa com um nível de conhecimento médio, com uma opinião um pouquinho mais sofisticada, acredita na Veja" (Nassif, 2008, p. 32), o fato é que ela ainda hoje lidera com imensa vantagem a lista de revistas mais vendidas no Brasil ${ }^{6}$.

Portanto, essa característica da revista Veja, que não tem nada de imparcial, vem sendo cada vez mais percebida por jornalistas independentes não vinculados aos grandes meios de comunicação, como também por historiadores ou demais estudiosos da imprensa. Este é o caso, por exemplo, da Carla Luciana Silva - professora do Programa de Pós-Graduação em História da Unioeste - que afirma que ao longo dos últimos anos, em especial durante os governos petistas, Veja foi firmando "um compromisso com o leitor, aquele de direita, reacionário, que encontrou na Internet um espaço para expressar sua visão de mundo" (2016, p. 131). O que Luciana Silva aponta é que Veja acabou por criar um 'contrato de leitura' com o "leitor mais reacionário possível. Conjunturalmente, parecem ser leitores que apóiam políticas neoliberais, muitos deles vinculados ou apoiadores do PSDB, e que circunstancialmente tem um discurso antigoverno" (2016, p. 131)

Em nosso estudo, foi possível observar, ao analisarmos as 50 edições publicadas durante o ano de 1989, que a revista Veja demonstrava, já desde essa época, um forte viés anti-esquerda e prócapitalismo liberal. Esse viés pode ser explicado também pelo contexto da época, marcado pelo

6. Segundo dados divulgados pelo Instituto Verificador de Circulação (IVC) no ano de 2007, a revista Veja liderava com folga a lista das dez revistas com maior vendagem no país. Veja aparecia em primeiro lugar com 1.096 mil exemplares mensais, enquanto a segunda colocada, a revista Época, vendia somente 428 mil exemplares (Corrêa, 2012, p. 229). 
enfraquecimento das utopias coletivas, fato que levaria a queda do muro de Berlim em novembro de 1989 e, dois anos depois, ao fim da URSS.

No tocante a política e a economia, Veja fomentava ideais liberais, de redução do Estado e de abertura econômica. Fazia isso ao escolher seus entrevistados, no tom das matérias e no apoio que fornecia aos candidatos alinhados com sua linha editorial. Deste modo, é possível afirmarmos que Veja foi um dos principais veículos da imprensa responsáveis pelo fomento das idéias liberais no país, incentivando sua nova onda, o neoliberalismo, que se estabeleceu no Brasil na década de 1990 e, atualmente, após os governos progressistas de Lula e Dilma, tem voltado a marcar presença no debate político atual.

\section{REFERÊNCIAS BIBLIOGRÁFICAS}

Augé, M. (1994). Não-lugares: introdução a uma antropologia da supermodernidade. Campinas: Papirus.

Abreu, A. A. (2002). A modernização da imprensa (1970 - 2000). Rio de Janeiro: Jorge Zahar Ed..

Anderson, P. (2010). Balanço do neoliberalismo. In E. Sader (org.), Pós-neoliberalismo: as políticas sociais e o Estado democrático (pp. 9-23). São Paulo: Editora Paz e Terra.

Biagini, H. (2016). Liberalismo elitista e republicanismo radical. In A. Sidekum (org.), Enciclopédia latino-americana dos direitos humanos (pp. 531-537). Edifurb; Nova Petrópolis: Nova Harmonia.

Biondi, A. (2014). O Brasil privatizado: um balanço do desmonte do Estado. São Paulo: Geração Editorial.

Boulos, G. (2015). De que lado você está?: reflexões sobre a conjuntura política e urbana no Brasil. São Paulo: Boitempo.

Bourdieu, P. (1996). A economia das trocas lingüísticas: o que falar quer dizer. São Paulo: Edusp.

Chauveau, A. \& Tétart, P. (1999). Questões para a história do presente. Bauru: EDUSC.

Chizzotti, A. (2010). Pesquisa qualitativa em ciências humanas e sociais. Petrópolis, RJ: Vozes.

Corrêa, T. S. (2012). A era das revistas de consumo. In A. L. Martins \& T. R. de Luca (org.), História da imprensa no Brasil (pp. 207-232). São Paulo: Contexto.

Cruz, H. de F. \& Peixoto, M. do R. da C. (2007). Na oficina do historiador: conversas sobre história e imprensa. Projeto História, (35). São Paulo.

Eizirik, M. F. (2005). Michel Foucault: um pensador do presente. Ijuí: Ed. Unijuí.

Fico, C. (2015). História do Brasil contemporâneo. São Paulo: Contexto.

Hayek, F. (1990). O caminho da servidão. Rio de Janeiro: Instituto Liberal.

Heywood, A. (2010). Ideologias políticas: do liberalismo ao fascismo. São Paulo: Ática.

Judt, T. (2011). O mal ronda a terra: um tratado sobre as insatisfações do presente. Rio de Janeiro: Objetiva. 
Judt, T. (2010). Reflexões sobre um século esquecido, 1901-2000. Rio de Janeiro: Objetiva.

Luciana Silva, C. (2016). A direita e sua imprensa: o papel da revista Veja. In F. Demier, \& R. Hoevler (org.), A onda conservadora: ensaios sobre os atuais tempos sombrios no Brasil (pp. 125-135). Rio de Janeiro: Mauad.

Mengarda, A. \& Brandão, L. (2015). Fernando Collor: o candidato esportista e as eleições de 1989. Recorde, 8 (1): 1-16. Rio de Janeiro.

Miguel, L. F. (2016). História e política, cultura e mídia. In R. L. Lohn (org.), História nas bancas de revistas: um país impresso: entre representações sociais e culturas políticas. Ponta Grossa: Todapalavra.

Mira, M. C. (2001). O leitor e a banca de revistas: a segmentação da cultura no século XX. São Paulo: Olho dÁgua/Fapesp.

Nassif, L. (2008). Entrevista explosiva: enfrentando a ferocidade da Veja. Revista Caros Amigos, março, (132): 28-34.

Pilagallo, O. (2009). A história do Brasil no século 20 (1980-2000). São Paulo: Publifolha.

Revel, J. (2005). Michel Foucault: conceitos essenciais. São Carlos: Claraluz.

Ribeiro, A. P. G. (2005). A mídia e o lugar da história. In M. Herschmann \& C. A. Messeder (orgs.), Mídia, memória e celebridades: estratégias narrativas em contextos de alta visibilidade, $2^{\mathrm{a}}$ Ed. Rio de Janeiro: E-Papers. 